\title{
Model Pengembangan Taman Wisata Alam Mooi Park Di Kota Sorong
}

\author{
Tunik Lindiani ${ }^{1}$, Rais Dera Pua Rawi ${ }^{2 *}$, Retno Dewi Wijiastuti ${ }^{3}$, Wisang Candra Bintari ${ }^{4}$, \\ Ahmad Jamil $^{5}$, Bekti Wiji Lestari ${ }^{6}$ \\ 1, 2, 3, 4, 5, 6 Universitas Muhammadiyah Sorong, Sorong, Indonesia \\ *E-mail: tuniklindiani99@gmail.com
}

\begin{abstract}
ABSTRAK
Pengembangan kepariwisataan mempunyai pengaruh yang positif bagi masyarakat terhadap perkembangan wilayah didaerah sekitar obyek wisata. Sama halnya dengan pariwisata di Kota Sorong, Sektor pariwisata bertindak sebagai sector utama, yaitu sector unggulan yang mampu meningkatkan perekonomian masyarakat. Penelitian ini dilakukan di Obyek Taman WisataAlam MOOI Park.Tujuan penelitian ini yaitu mendeskripsikan Model Pengembangan Taman Wisata Alam MOOI Park di Kota Sorong. Jenis penelitian yang digunakan dalam penelitian ini adalah penelitian deskriptif dengan pendekatan kualitatif dan metode pengumpulan data menggunakan wawancara, observasi dan dokumentasi. Hasil penelitian menunjukkan bahwa Model Pengembangan Taman Wisata Alam MOOI Park di Kota Sorong, memiliki potensi dan daya Tarik untuk menjadi salah satu destinasi yang wajib di kunjungi oleh pengunjung. Objek wisata inimemiliki pepohonan yang indah dan halaman yang luas serta pemandangan tarian ombak yang dahsyat di sepanjang pesisir MOOI Park dengan di suguhkan ukiran patung tangan manusia yang sangat unik. Beberapa fasilitas yang memadai Sehingga wisatawan dapat melakukan berbagai macam pilihan aktifitas wisata di objek wisata ini dan selalu ada perubahan atau pembaharuan yang dilakukan oleh pemilik usaha pariwisata ini agar lebih menarik setiap saat berkunjung.
\end{abstract}

Kata kunci : Model Pengembangan, Taman Wisata Alam, MOOI Park

\section{Mooi Park Natural Tourist Development Model In The City Of Sorong}

\begin{abstract}
The development of tourism has a positive influence on society. Towards the development of the area around the tourist attraction. Same is the case with tourism in Sorong City. The tourism sector acts as the main sector, namely the leading sector that is able to improve the economy of the community. This research was conducted at the MOOI Park Nature Tourism Object.The purpose of this study is to describe the Development Model of MOOI Park Nature Tourism Park in Sorong City. This type of research used in this research is descriptive research with a qualitative approach and data collection methods using interviews, observation and documentation.The results showed that the Mooi Park Nature Park Development Model in Sorong City has the potential and attractiveness to be one of the destinations that must be visited by visitors. This tourist attraction has beautiful trees and a large yard and a great view of the dance of the waves along the coast of MOOI Park by being presented with carvings of human hands that are very unique. Some adequate facilities So that tourists can make various choices of tourist activities in this tourist attraction and there are always changes or updates made by the owner of this tourism business to make it more interesting every time you visit.
\end{abstract}

Keywords: Development Model, Nature Tourism Park, MOOI Park 


\section{PENDAHULUAN}

Kehidupan ekonomi di Indonesia telah berubah seiring dengan berlangsungnya proses globalisasi ekonomi dan banyaknya temuan baru dibidang teknologi komunikasi dan informasi, telah mengiring pelakubisniskedalam suatu tempat interaksi sosial yang baru yang belum pernah terbayangkan sebelumnya, dan hal itu sama sekali belum terdeteksi. Kondisi kehidupan ekonomi di Indonesia saat ini telah memasuki perputaran baru yang disebut sebagai ekonomi kreatif.

Ekonomi kreatif adalah suatu konsep perekonomian di era ekonomi baru yang mengintensifkan informasi dan kreativitas dengan mengedepankan ide dan pengetahuan dari sumberdaya manusia sebagai factor produksi yang paling utama. Kementerian Perdagangan Indonesia menyebutkan bahwa ekonomi kreatif merupakan suatu upaya pembangunan ekonomi secara berkelanjutan melalui kreativitas dengan iklim perekonomian yang berdaya saing dan memiliki cadangan sumberdaya yang terbarukan.

Taman wisata alam adalah kawasan hutan konservasi yang bias dimanfaatkan untuk kegiatan pariwisata dan rekreasi. Kegiatan pariwisata yang dilaksanakan di hutan wisata alam tidak boleh bertentangan dengan prinsip konservasi dan perlindungan alam. Karena pada hakikatnya taman wisata alam masuk dalam kawasan pelestarian alam.

Untuk mengatasi permasalahan tersebut diperlukan campur tangan dari pihak-pihak dibidangnya. Pemerintah memang berperan penting dalam penyelesaian ini, namun selain dari pemerintah banyak pihak yang berperan serta dalam pengembangan pariwisata di Kota Sorong khususnya MOOI Park.

Taman WisataAlam MOOI Park adalah salah satu Taman WisataAlam yang sering menjadi bahan pembicaraan masyarakat di Kota Sorong karena budget yang dikeluarkan sangat terjangkau dan model pengembangannya sangat menarik dan kreatif.

Model pengembangan taman wisata MOOI Park selalu mengalami perubahan dari hari kehari, berdasarkan permintaan dari pengunjung yang begitu tinggi, model dan fasilitas yang di berikan oleh taman wisata moi park terdiri dari, mushola, kolam renang dewasa, kolam renang anak- anak, kantin, game paint ball, odong-odong, sepeda dewasa dan anak, tempat penginapan, dan lebih unik lagi taman wisata moi park langsung berhadapan dengan laut, sehingga para pengunjung bias langsung menikmati suasana pantai dan bias berenang dilaut.

\section{METODE}

Jenis penelitian yang digunakan dalam penelitian ini adalah penelitian deskriptif dengan pendekatan kualitatif. Disini penulis menggambarkan atau menjelaskan bagaimana Model Pengembangan Taman Wisata Alam MOOI Park di Kota Sorong. Metode penelitian deskriptif adalah mencari teori, bukan menguji teori.Metode ini menitik beratkan pada observasi. Peneliti bertindaks ebagai pengamat, ia hanya mengamati gejala dan mencatatnya dalam buku observasi. Dengan susasana ilmiah berarti bahwa peneliti terjun kelapangan. Ia tidak berusaha memanipulasi variabel. Hasan (2002:22)."

Pendekatan kualitatif menurut Santana (2007:29) menyatakan bahwa "memproses pencarian gambaran data dari konteks kejadiannya langsung, sebagai upaya melukiskan peristiwa sepersis kenyataannya, yang berarti membuat berbagai kejadiannya seperti merekat dan melibatkan perspektif (peneliti) yang partisipatif di dalam berbagai kejadiannya, serta menggunakan pendikduksian dalam gambaran fenomena yang diamatinyaa". Metode atau teknik yang digunakan dalam pengumpulan data adalah: wawancara, observasi, dokumentasi.

\section{HASIL DAN PEMBAHASAN}

MOOI Park merupakan tempat wisata alam yang terletak di Kota Sorong, beralamat di Jln. Obet Mubalus No.999 Saoka Papua Barat. Dibuka pada tanggal 15 Juni 2018 didirikan oleh Johan Ang. Tempat wisata ini berupa pemandangan alam yang indah dengan suasana yang tenang dan nyaman. Dilengkapi dengan berbagai fasilitas seperti WC umum, kolam berenang 
anak-anak, musholah, resort. Dan yang baru di buka pada pertengahan tahun 2019 ini yaitu games paint ball.

Hasil wawancara ( bapak johan Ang) menjelaskan bahwa. Pada tahun 2000 tempat wisata alam MOOI park dahulunya tempat ini hanyalah resort biasa untuk peristirahatannya dan hanya sering dikunjungi oleh teman-temannya. Melihat peluang bisnis yang bagus sehingga memutuskan untuk membuka tempat wisata alam dari saran yang teman-temannya berikan.

Karena kurangnya tempat wisata di Kota Sorong maka kesempatan untuk melakukan peluang bisnis ini akan sangat menguntungkan. Membangun tempat wisata alam yang menarik perhatian orang-orang dengan berbagai macam fasilitas dan harga yang terjangkau. Memulai usahanya dengan bermodal akan tekat yang kuat, usaha yang tekun, kejujuran, dan kepercayaan. Bapak johan merupakan orang yang cinta alam, dengan rasa cintanya kepada alam ia Metode atau teknik yang digunakan dalam pengumpulan data adalah: wawancara, observasi, dokumentasi berharap bias mendapatkan keuntungan yang menjadi tabungan di hari tuanya.

Pengolahan objek wisata alam MOOI park memerlukan perhatian khusus sehingga dapat mengakomodir kebutuhan semua pihak baik pengunjung, masyarakat di sekitarobjekwisataalam. Wisataalam MOOI park merupakan objek wisata alam yang ada di kota sorong perlu menambahkan suatu usaha yang lebih kreatif lagi agar objek wisata alam tersebut dapat memberikan dampak positif sehingga perekonomian masyarakat setempat dapat tumbuh dan berkembang.

Penelitian ini bertujuan untuk memberikan gambaran potensi pengembangan ekonomi kreatif di objek wisata alam MOOI Park sehingga dapat meningkatan daya tarik objek wisata alam tersebut. Tahapan yang dilakukan adalah menjelaskan potensi objek wisata kemudian menganalisisnya berdasarkan aspek daya tarik sebuah objek wisata alam dalam ekonomi kreatif. Objek wisata alam MOOI park memiliki potensi alam namun jika dilihat melalui aspek daya tarik yaitu aktivitas, fasilitas, karya seni dan lain-lain, maka objek ini masih perlu lagi di tamabahkan agar menjadi tempat yang ramah dan menarik untuk di kunjungi.

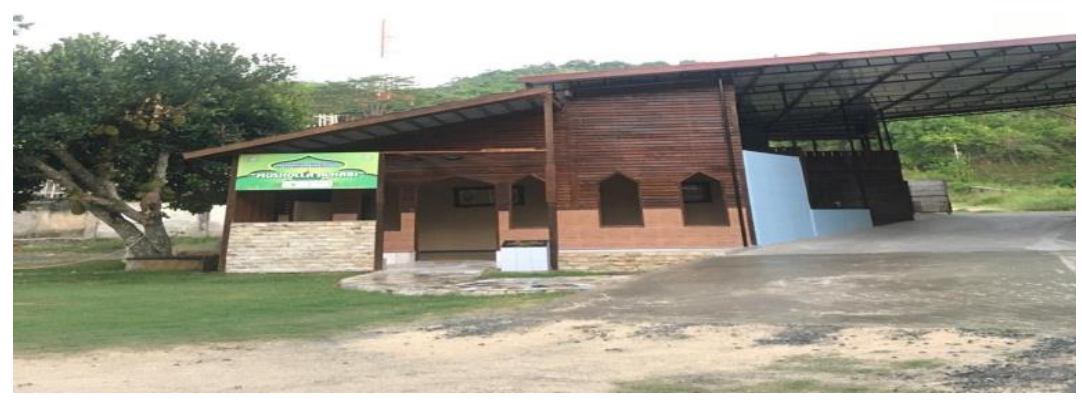

(Gambar 1. Mushola)

Sebelum MOOI Park semakin berkembang tidak terdapat mushola, tetapi dengan pertambahan pengunjung yang semakin ramai pemilik usaha ingin memberikan fasilitas yang terbaik kepada pengunjung, yaitu dengan membangun mushola. Sebelumnya jika pengunjung ingin melaksanakan sholat, mereka melakukannya di salah satu kamar penginapan yang ada di MOOI Park. 


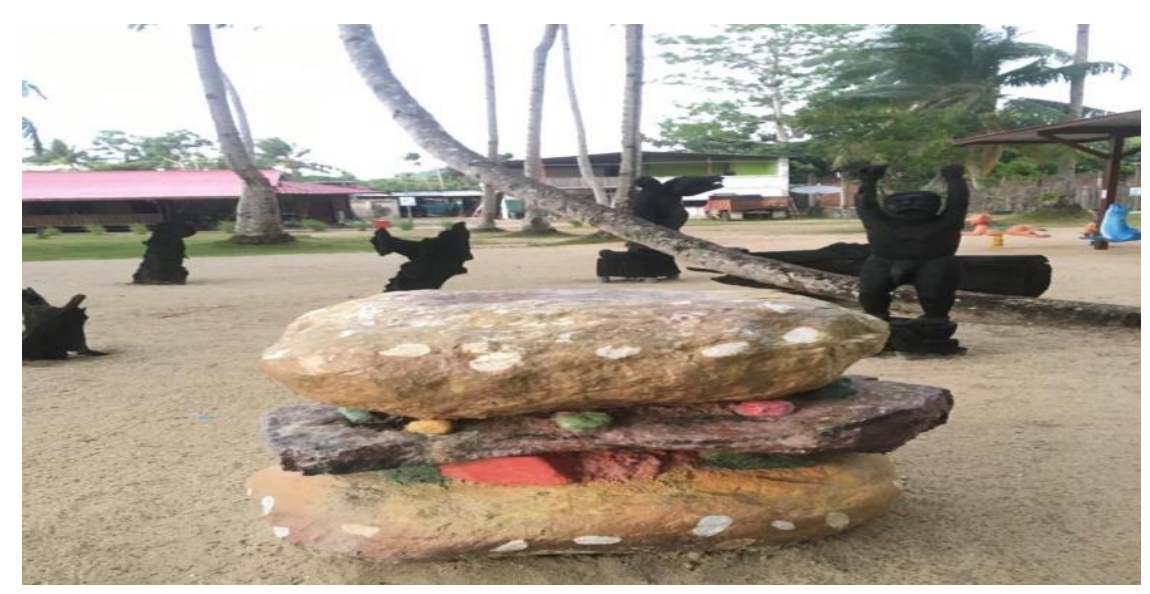

Gambar 2. Patung Kerajinan Tangan dan Batu Hamburger

Menjadikan bebatuan besar seperti makanan Hamburger dengan paduan cat yang membuat semakin nyata dan Terdapat ukiran patung berasal dari kayu bekas dibakar yang di pahat oleh pengrajin yang di datangkan langsung dari raja ampat membuat MOOI Park lebih menarik lagi untuk dikunjungi. Ini pengembangan yang dilakukan oleh pemilik MOOI Park agar pengunjung berfoto disini dan mengunggahnya di sosial media sehingga banyak yang tertarik dan mengunjungi Taman Wisata Alam MOOI Park.

Saat ini yang menjadi tantangan dalam usaha ekonomi kreatif terutama dalam bidang pariwisata adalah semakin banyaknya "competitor". Karena dengan pesatnya perkembangan industry pariwsata, baik ditingkat Nasional maupun dunia, destinasi objek wisata dihadapkan dengan persaingan yang cukup ketat. Persaingan dapat menyebabkan pengunjung memperoleh banyak pilihan, oleh karena itu agar destinasi objek wisata dapat di pilih oleh mayoritas para pengunjung, maka destinasi harus dapat memenangkan persaingan dengan cara melakukan stategi bersaing yang tujuannya agar unggul dalam lingkungan persaingan.

Selain itu, kualitas sumber daya manusia (SDM) di sector pariwisata masih banyak yang tidak terampil. Pengembangan wisata di daerah terkadang muncul permasalahan yang berasal dari adanya kesengajaan kondisi lingkungan dan system sosial. Pemerintah daerah sebagai perencana, pelaksana, dan pengontrol dalam sebuah kebijakan daerah di harapkan mampu menganalisis dan memetakan permasalahan yang terjadi dalam masyarakat dan sesuai kebutuhan masyarakat.

Masalah dapat timbul karena kebijakan antara pemerintah daerah yang tidak konsisten. Kadang muncul ego kepentingan masing-masing pihak dapat menghambat pengembangan wisata. Akibat kepentingan yang tidak sama menyebabkan daerah wisata tidak us dan pengunjung enggan untuk berkunjung.

\section{SIMPULAN}

Dari hasil penelitian diatas dapat ditarik kesimpulan sebagai berikut bahwa pengembangan pariwisata yang baik akan menciptakan berbagai efek yang salah satunya adalah meningkatkan pendapatan daerah dan masyarakat setempat. Disarankan kepada pemerintah daerah untuk lebih memperhatikan terkait dengan pengembangan pariwisata. Model pengembangan Taman Wisata MOOI Park yang diperbaharui setiap harinya dapat menjadi peluang untuk para seniman yang ingin berkarya dan dapat membantu kehidupan masyarakat dan dapat menjadi factor penyebab kemajuan Pariwisata di Kota Sorong. Adanya pariwisata mencegah terjadinya abrasi atau pengikisan pantai oleh tenaga gelombang laut. 


\section{DAFTAR PUSTAKA}

Fandeli, Chafid (ed). 1995. Dasar-dasarManajemenKepariwisataanAlam. Yogyakarta :Penerit Liberty.

Yoeti, Oka A. 2008. Perencanaan dan PengembanganPariwisata. Penerbit PT. Pradnya Paramita, Jakarta

Karyono, A. Hari. 1997. Kepariwisataan. Jakarta: Gramedia Widiasarana Indonesia.

Sedarmayanti, 2004. Membangun Dan MengembangkanKebudayaan Dan IndustriPariwisata. PenerbitRefikaAditama.

Ridwan, Mohammad.2012. perencanaanPariwisata dan PengembanganPariwisata, Medan Polonia: PT. Sofmedia

https://www.researchgate.net/publication/320211194_MODEL_PENGEMBANGAN_PARIWI SATA_BERBASIS_MASYARAKAT_DI_KOTA_YOGYAKARTA

http://madebayu.blogspot.com/2012/02/model-pengembangan-pariwisatapedesaan_3671.html 